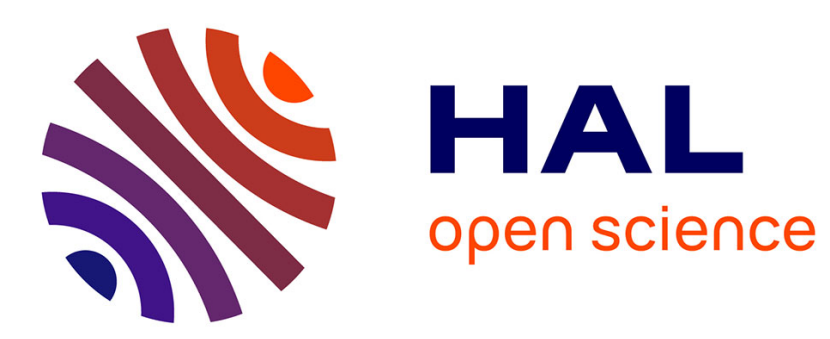

\title{
Textbook publishers' website objective question banks
}

Scott Paul Johnston, Andrzej Huczynski

\section{To cite this version:}

Scott Paul Johnston, Andrzej Huczynski. Textbook publishers' website objective question banks. Active Learning in Higher Education, 2006, 7 (3), pp.257-271. 10.1177/1469787406069057 . hal00571952

\section{HAL Id: hal-00571952 \\ https://hal.science/hal-00571952}

Submitted on 1 Mar 2011

HAL is a multi-disciplinary open access archive for the deposit and dissemination of scientific research documents, whether they are published or not. The documents may come from teaching and research institutions in France or abroad, or from public or private research centers.
L'archive ouverte pluridisciplinaire HAL, est destinée au dépôt et à la diffusion de documents scientifiques de niveau recherche, publiés ou non, émanant des établissements d'enseignement et de recherche français ou étrangers, des laboratoires publics ou privés. 


\title{
Textbook
}

publishers'

\section{website objective question banks}

Does their use improve students'

examination performance?

\author{
SCOTT PAUL JOHNSTON Civil Service, UK
}

\author{
ANDRZEJ HUCZYNSKI University of Glasgow, UK
}

\begin{abstract}
This article presents the findings of a survey of students' usage of the objective question bank section of an academic publisher's textbook website. The findings are based on a survey of 239 business and management undergraduates conducted using a quantitative research methodology. The results suggest that increased use of the objective question bank improves students' examination performance only where it matches exactly the course assessment format. Other factors, such as usage cross-tabulated with gender and off-campus Internet access were also examined. On the basis of this survey, the authors consider the use of textbook publishers' objective question banks in teaching business and management subjects at university. KEYWORDS: business, management, objective tests, survey, textbook publishers' student websites, undergraduate
\end{abstract}

\section{Introduction}

Textbook publishers' student websites represent an increasingly important aspect of higher education that has, to date, been neglected. These websites have been developed by, and are maintained for student use by academic publishers, specifically to accompany their individual textbooks. All the major academic publishers now host multiple textbook websites. Past research into publishers' uses of their websites is limited, and focuses upon their role in online selling directly to customers (Kipling and Wilson, 2000); their use as sales, adoption or public relations tools (Posey, 2000); how publishers put tables of content, abstracts and the full-text of their print 
journals onto the Web (Scheschy, 1999; Peek et al., 1998); and publishers' e-books and electronic publishing processes (Shiratuddin, 2005).

None of this literature gives any indication that publishers possess textbook websites. Tookey's (2002) review of two such websites was amongst the first in an educational academic journal, and drew attention to their existence. There are several reasons for investigating them. First, having a textbook website is now considered essential by publishers. In the last decade, the major publishing houses have all invested money into online learning resources to support their textbooks. In 1998, it was estimated that 83 per cent of UK-based publishers had a presence on the Internet (Stone, 1998), a figure that must now have reached 100 per cent. Second, probably the simplest, cheapest, fastest and most effortless way in which academics can augment their courses with a web-based, student learning resource, is to select a course textbook that has a website associated with it. Third, the increasing use of virtual learning environments (VLEs) within universities is encouraging the provision of interactive resources for students. Most VLEs contain facilities for instructors to develop their own banks of objective questions. All VLEs allow linkages to textbook publishers' question banks. Thus, if one were looking for an example of a computer-related resource that was most easily introduced into universities, then the publishers' textbook website would offer itself as an obvious candidate.

Johnston and Huczynski (2004) investigated the contents of these websites. They examined 175 different textbook websites, maintained by 6 different publishing companies relating to business and management subjects. They identified 698 items which were classified into 11 distinguishable categories of learning resource, and one large, residual one. They found that, in terms of the frequency of occurrence, objective test questions (multiple choice, true-false, fill-in-the-blank, matching) represented the single largest resource available to students (see Table 1). The publishers' textbook website's objective question bank (OQB), its use and impact on student examination performance, is the focus of this study. The large residual category, containing 112 items, included a collection of items which, it appears, sought to attract students to the site. Among the items found were games, study advice, career advice, fashion hints, free music and contests to win money. The diversity of these items precluded further useful classification.

\section{Literature review}

Do students studying courses which have an associated core textbook that has an objective question bank use it? If they do, does it improve their 
JOHNSTON \& HUCZYNSKI：PUBLISHERS' QUESTION BANKS

Table 1 Frequency of resources appearing on publishers' textbook websites

\begin{tabular}{llrc}
\hline Ranking & Student learning resource & No. & \% of total \\
\hline 1 st & Other & 112 & 64.0 \\
2 & Web links & 108 & 61.7 \\
3 & Objective test questions (multiple choice) & 102 & 58.3 \\
4 & Updates & 68 & 38.9 \\
5 & Internet activities & 65 & 37.1 \\
6 & Objective test questions (true-false) & 61 & 34.9 \\
7 & Learning objectives & 61 & 34.9 \\
8 & Glossary & 46 & 26.2 \\
9 & Written answer questions & 38 & 21.7 \\
10 & Case studies & 31 & 17.7 \\
11 & Objective test questions (fill-in-the-blank) & 3 & 1.7 \\
12 & Objective test questions (matching) & 3 & 1.7 \\
Total & & 698 & \\
\hline
\end{tabular}

Source: Johnston and Huczynski (2004: 51)

performance in examinations? The literature review did not reveal any empirical investigations into students' use of publishers' OQBs, or into the relationship between their use and the students' examination performance in any subjects. Within the authors' own field of business and management, most past research has focused either on the more general question of the feasibility of using computer assisted learning (CAL) in business and management subjects (Bigelow, 1999; Meisel and Marx, 1999), or else has investigated student attitudes to CAL in business and management courses (Arbaugh, 2000; Human et al., 1999). There have been some studies into students' use of CAL in general. Authors like Davies and Crowther (1995), Spellman (2000) and Goffe and Soskin (2005) argue that CAL can offer a more enriching learning experience for the student, increasing their motivation to learn, and facilitating active learning. However, how often this happens in practice needs to be examined in detail as CAL materials vary considerably. Apart from publishers' textbook websites, other Internet sites provide multimedia lectures, with features such as audio and video (Bland, 2002). Haworth and Davidson (2000) argued that the greater the diversity of resources on a CAL website, the more frequently the website would be used by students, as students possessed a variety of different learning styles.

Bigelow's study of a transition from a conventional classroom-based organizational behaviour course to an Internet-based one, showed that the latter could offer learning benefits for students. These included greater selfmanaged learning, and the possibility of instant feedback for students who participated in examinations (Bigelow, 1999). Ward and Newlands (1998) 
also found that CAL applications gave students greater choice of when to study. Despite these advantages, Bigelow stressed that CAL may have a negative impact on activities that emphasise face-to-face interaction, though this may be reduced as computers and CAL technologies develop in the future. Merisotis and Phipps (1999) reported research which revealed that the learning outcomes of students using technology at a distance are similar to those who participate in convention classroom instruction. The authors go on to highlight the shortcomings of the comparative research on this topic.

There is also a research literature that takes a more managerial approach, looking at the benefits for universities of implementing CAL applications. McInnes et al. (1995) argued that there had been increased pressure on academic staff to publish as a result of regular, institutional research assessments. Coupled with increasing student numbers and budget constraints, they suggested that an investment in CAL should only take place if it reduced costs and freed up time for academic staffs' research. Indeed, Ward and Newlands (1998) noted that CAL had a great potential to benefit student learning, but involved a considerable investment of time for lecturers who had to prepare CAL materials, if ready-to-use packages were not available commercially. McInnes et al. (1995) also argued that the use of CAL should be justified in terms of monetary cost.

What studies have been conducted of potential CAL users? Our literature search indicated that there were few studies profiling the users of CALbased business and management-related courses. Consequently, we had to draw upon studies from other social science fields. With regard to economics courses, there appeared to be no gender-specific characteristics determining student usage of CAL (Haworth and Davidson, 2000). This finding was also replicated for psychology courses (Grabe and Sigler, 2002; Wang and Newlin, 2000), and for those on an education course (Barrett and Lally, 1999). Haworth and Davidson suggest those who underperformed in class examinations may be inclined to start using CAL to correct their performance in time for the final examination. Grabe and Sigler suggested that the level of students' computer literacy was not a crucial factor in determining their use of CAL. Therefore the literature suggests that various factors can determine the use of CAL by students.

What is the relationship between using CAL and examination performance? Sangster (1992) suggested that CAL applications could take two forms: supplantive, the substitution of conventionally delivered lectures; and supportive, reinforcing traditionally delivered lectures and tutorials. The literature search indicated that there were few studies comparing the success of CAL-based business and management-related courses vis-à-vis those delivered by conventional classroom means. Consequently, studies from other 
social and information sciences were considered. Supportive CAL applications, such as publishers' textbook OQBs are those which reinforce traditionally delivered lectures and tutorials. The literature did not reveal any studies examining the use of supportive CAL applications within business and management subjects. In psychology, the literature suggests unanimously that supportive CAL applications do facilitate student performance. In a study by Worthington et al. (1996), students who used a supportive CAL application for an introductory psychology class attained higher examination scores. Higher examination scores were also found among students who had used supportive CAL applications for introductory psychology courses in research studies conducted by Buchanan (2000), Grabe and Sigler (2002) and Maki and Maki (2001).

With regard to economics, MacDonald and Shields (1998) showed that students' use of the WinEcon CAL software to supplement their studies improved their examination performance. Kennedy et al. (1998) showed that students who used CAL to support their introductory economics course achieved better grades than non-users. However, a study of an introductory accountancy course by McInnes et al. (1995) found no difference in examination performance between users and non-users of a CAL application. As with the literature review of McInnes et al. (1995), no students who used supportive CAL applications received inferior grades to non-users. In information science courses, McIntyre and Wolff (1998) found that students who used a supportive CAL application for an introductory computer programming course achieved higher examination grades than those who did not. Consequently, on this basis of this literature, it would appear that students who made use of supportive CAL applications, generally tended to achieve higher examination grades. If using CAL increased their examination grades, then one would expect that they would be more motivated to use it (Davies and Crowther, 1995; Spellman, 2000). The authors' expectations therefore were that students who had used the question bank, would attain higher examination grades than those who had not.

Despite such research, the authors had to take into consideration that students' entry qualifications into university as a confounding factor on this research. Superior examination and test performance may be due to the fact that a student was generally of high academic calibre, and could have nothing to do with their use or non-use of CAL. That is, those who were high achievers in the past would continue to be so in the future. However, Tuckman (2000) suggests that increased test practice will lead to increased performance, with the possibility of school under-performers gaining higher scores than those with previously higher performance at school. Consequently, respondents were also divided on the basis of their university entry grades. 
The literature review revealed a total neglect of publishers' textbook websites, including their objective question bank sections. There have been studies into students' use of supportive CAL applications, but not specifically into computerized objective test banks. Those studies of CAL applications that have been carried out, suggest that their use by students does improve their examination scores. In the light of these omissions and gaps in the literature, this study had three aims. First, to identify the extent of use made by students of the publishers' textbook objective question bank that accompanied their course's core textbook. It sought to identify factors that promoted or lessened their use; and the value that students gained from it, in terms of perceived benefits and actual benefits in midterm and final examination performance. The literature suggests that CAL in general offers a wide range of advantages for the student user. Consequently, a number of hypotheses were proposed for testing with respect to the publishers' textbook objective question bank. They sought to answer three related questions. Whether those students who used the publishers' textbook objective question bank, would feel there was a good range of resources available (1a); whether they felt that open-access use allowed them greater flexibility in their study activities (1b); and whether the summary feedback facility was useful (1c).

Second, with regard to the characteristics of student users, the study sought to examine if the factors found in the literature review concerning propensity to use CAL applications, were relevant to first year, business and management students. The hypotheses sought to determine whether the degree of usage of the publishers' textbook objective question bank was influenced by students' gender or by their off-campus accessibility to the Internet. Third, with regard to possible links between students' use of the publishers' textbook objective question bank and their examination performance, the hypotheses sought to investigate whether the degree of usage of the publishers' textbook objective question bank influenced students' class test results; whether it influenced their final examination results; whether there was a correlation between university entry grades and class test performance; and finally, whether there was correlation between students' university entry grades and their examination performance.

\section{Methodology}

The first year, foundation Business and Management course at the authors' university focuses on organizational behaviour and management topics. Its course textbook (Buchanan and Huczynski, 2004) has a companion website containing a bank of objective questions. That bank currently contains over 2500 objective questions (http://www.booksites.net/buchuc). This 
website and its associated question bank is maintained by Pearson Education. Organised by chapter, the question bank allows students to revise the textbook material. It includes different question formats: multiple choice (at the knowledge and comprehension levels), fill-in-the-blank, matching and true-or-false. Users obtain instantaneous feedback on their performance under timed conditions. This includes their answers being displayed alongside the correct answers, as well as the time that they have taken to complete each test. The site is available continuously; can be accessed from anywhere in the world; and test results are known only to the student users (staff do not keep a record). All academic publishers promote their textbooks to potential lecturers using the argument that the associated companion website, containing objective tests, will encourage students' revision, enhance their learning and improve their overall examination performance in the course. By implication, they suggest that student performance in nonobjective question exam formats, will also be enhanced.

Like many similar courses, the present first year, foundation course currently has a multiple assessment structure, and mixes objective testing with other assessment formats, so as to assess students' achievement as widely as possible. As shown below, pencil-and-paper objective tests count for 45 per cent of the total student assessment on this course. These tests match exactly those found on the website just described:

- a class test consisting solely of objective questions, worth 20 per cent of the total course grade;

- a written, 2000 word assignment, worth 30 per cent of the total course grade;

- a final, degree examination consisting a set of (compulsory) objective test questions and one (chosen) written essay answer, each worth 25 per cent of the total course grade.

A sample plan was used to define the study population, ensuring the data obtained was as accurate as possible. Within this study, convenience sampling methods were used, whereby respondents were selected on the basis of convenience to the researcher. Respondents were selected for both the pilot testing and main data collection stages in this way. This was done because a sufficient sampling frame was unavailable owing to confidentiality issues related to students' personal data. Furthermore, the population was readily available, and concentrated in only two locations. Sample size affects the accuracy of the results. Owing to the fact that convenience sampling was used, the sample size reflected all the students present on the day of data collection, 284 respondents. Although the sample was biased to the extent that it reflected members of the class that were present on that day, questionnaires were distributed to everyone and all forms were 
returned, thus eliminating any socio-demographic biases which would have otherwise rendered the study invalid.

If further information regarding the composition of the sample had been available, the researchers could have adopted a probability sampling method. Only 86 respondents would have been needed to attain a statistical confidence level of 95 per cent from a class roll of 442 .

For the collection of primary data, the quantitative research approach was favoured, owing to the large number of respondents. A questionnaire was chosen to collect the empirical data. To test the hypotheses stated earlier, a 60-item questionnaire was developed (after piloting), using variables drawn from the studies identified in the literature review. This questionnaire also included variables for additional academic research and course evaluation purposes. The majority of the questions included were response questions. They consisted of a statement, for example, 'I found the question bank easy to use', followed by a five-point modified Likert interval scale, in which each descriptor in the scale is exactly one unit away from the preceding one. The exceptions to this were questions such as 'Do you have off-campus access to a personal computer?', which are nominal-scaled questions. In addition to these questions, each respondent's matriculation number was collected so that the respondents' survey responses could be anonymously linked to their class test, final examination results and university entry grades. Of the 284 questionnaires distributed, 45 questionnaires were returned incomplete or completed incorrectly. These were discarded as many of these questionnaires had boxes scored that were not an option provided in the multiple choice question, suggesting that the respondent was not interested in giving accurate answers. The final sample size of $n=239$ reflects an 84.1 per cent response rate. From Table 2, it can be observed that the majority of the sample, 54.8 per cent, was female, and the majority of the sample, 47.7 per cent, was aged 18.

From Table 3, it can also be observed that the majority of respondents, 51.5 per cent, were from the Social Science faculty, and that 89.1 per cent of respondents were in their first year of university study.

\section{Results}

The results of the 239 questionnaires returned were analysed using the software package SPSS 11.5 for Windows. The data was re-coded from alphabetical to numerical form. The first stage of the statistical analysis involved calculating the percentage response for each variable for a subjective impression of the data. The mean response and standard deviation of each variable were also calculated. Next, the statistical tests for the hypotheses stated earlier were completed. For each test, assumptions underlying 
JOHNSTON \& HUCZYNSKI：PUBLISHERS' QUESTION BANKS

Table 2 Gender and age of the sample

\begin{tabular}{lccccc}
\hline Gender & Frequency & Percentage & Age & Frequency & Percentage \\
\hline Female & 131 & 54.8 & $21+$ & 20 & 8.4 \\
Male & 108 & 45.2 & 20 & 19 & 7.9 \\
& & & 19 & 44 & 18.4 \\
& & 18 & 114 & 47.7 \\
& & 17 & 42 & 17.6 \\
\hline
\end{tabular}

Table 3 Faculty and year of study of the sample

\begin{tabular}{lccccc}
\hline Faculty & Frequency & Percentage & Year & Frequency & Percentage \\
\hline Arts & 48 & 20.1 & 1 st & 213 & 89.1 \\
Law \& Financial & 7 & 2.9 & 2 nd & 18 & 7.5 \\
$\quad$ Studies & 55 & 23.0 & $3 r d$ & 7 & 2.9 \\
Science & 123 & 51.5 & 4 th & 1 & 0.4 \\
Social Science & 6 & 2.5 & & & \\
Other & & & & &
\end{tabular}

their use such as large sample size and independent observations were verified before they were employed. In all tests requiring comparisons between groups, utilizing a Bonferroni, multiple comparisons procedure, there was a statistically significant difference between groups if the 'p-value' of the test was less than 0.05 , a benchmark widely accepted in academia and professional statistical analysis.

The results obtained from that research are presented in two steps. First, usage patterns of the question bank by students are considered. These are followed by an analysis of the results of the statistical techniques employed to test the hypotheses presented earlier. With respect to question bank usage patterns, Table 4 indicates that two-thirds of students used the bank with the majority indicating that they used it sometimes or frequently. Table 5 also indicates that the majority of students, 73.3 per cent, used it alone, with only 7.6 per cent working in a group of three or more. The following subsections will now present an analysis and discussion of the results of statistical tests employed for each individual hypothesis.

\section{Why use the question bank?}

As hypotheses 1a to 1c involve interval scales (coded from $5=$ strongly agree, to 1 = strongly disagree), relevant questionnaire variables were compared in a one-sample t-test against the value 3, representing the 
Table 4 Usage of question bank

\begin{tabular}{lcc}
\hline & Frequency & (\%) \\
\hline Always & 29 & 12.1 \\
Frequently & 48 & 20.1 \\
Sometimes & 55 & 23.0 \\
Rarely & 26 & 10.9 \\
Never & 81 & 33.9 \\
\hline
\end{tabular}

Table 5 Number of users

\begin{tabular}{lcc}
\hline Number of users & Frequency & Proportion (\%) \\
\hline In a group of 3 or more & 12 & 7.6 \\
With a partner & 30 & 19.1 \\
Alone & 115 & 73.3 \\
\hline
\end{tabular}

neutral scale-item on the questionnaire, to indicate the direction of agreement or disagreement to a variable (Table 6).

As all the p-values are less than 0.05 , this indicates a significant difference greater or lesser than 3 on the agreement-disagreement scale, with the strength of the difference illustrated by the 95 per cent confidence interval. Consequently, in line with hypothesis 1a, students who used the question bank felt there was a good range of resources available. Furthermore, concurrent with hypothesis $1 \mathrm{~b}$, students who used it felt that open-access use allowed them greater flexibility in their study activities. Finally, corresponding to hypothesis 1c, students who used the question bank found the summary feedback facility useful.

\section{Characteristics of question bank users}

To formally test hypothesis $2 \mathrm{a}$, which stated that the degree of usage of the bank is not influenced by students' gender, a two-sample chi-square test was employed. The Pearson chi-square statistic was 0.75 with a significance (p) value of 0.95 . Consequently, there was no significant difference in usage of the bank in terms of gender. To formally test hypothesis $2 \mathrm{~b}$, which stated that the degree of usage of the bank is influenced by off-campus accessibility to the Internet, a two-sample chi-square test was employed. The Pearson chi-square statistic was 1.52 with a significance (p) value of 0.82 . Consequently, there was no significant difference in usage of the bank in terms of off-campus access to the Internet. 


\section{Use of question bank and examination performance}

From Table 7, it appears that those who always used the bank had the highest mean class test grades, with those rarely using the bank having the lowest mean class test grades. Similarly, it appears that those who always used it had the highest mean final examination grades, with those rarely using it had the lowest mean class test grades.

To formally test hypotheses $3 \mathrm{a}$, which stated that the degree of usage of the bank will affect mean class test results, and $3 b$, which stated that the degree of usage of the bank will affect mean final examination results, two separate One-Way ANOVAs were employed. Statistically significant differences were found in class test grades for the five degrees of usage $[F=9.24$, $\mathrm{p}=0.00]$. Post-hoc comparisons indicated where those differences lie, illustrated in Table 8, with the underlined degree of usage having a higher mean. However, there were no statistically significant differences found in final examination grades for the five degrees of usage [ $\mathrm{F}=1.59, \mathrm{p}=0.18$ ].

To formally test whether or not university entrance grades were correlated with class test performance, a Pearson correlation was computed for university entry qualifications data against class test performance. It was found that there was a significant correlation $[r=0.319, p=0.00]$ at the $\mathrm{p}=0.05$ level of confidence. Thus, there is a low, positive relationship

Table 6 One-sample t-tests for hypotheses 1a-1c

\begin{tabular}{|c|c|c|c|c|c|c|}
\hline \multirow[b]{2}{*}{ Hypothesis } & \multirow[b]{2}{*}{ Mean } & \multirow[b]{2}{*}{ Std. deviation } & \multirow[b]{2}{*}{ t-statistic } & \multirow[b]{2}{*}{$p$-value } & \multicolumn{2}{|c|}{ 95\% Confidence interval } \\
\hline & & & & & Lower & Upper \\
\hline $1 \mathrm{a}$ & 4.44 & 0.73 & 24.86 & $0.00^{\star}$ & 1.32 & 1.55 \\
\hline $1 b$ & 3.74 & 0.90 & 10.46 & $0.00^{*}$ & 0.60 & 0.88 \\
\hline $1 c$ & 4.32 & 0.78 & 21.20 & $0.00^{*}$ & 1.20 & 1.45 \\
\hline
\end{tabular}

* Significant at $p=0.05$

Table 7 Average examination performance by usage of question bank

\begin{tabular}{lcccc}
\hline Degree of usage & $\begin{array}{c}\text { Class test } \\
\text { mean } \\
(\%)\end{array}$ & $\begin{array}{c}\text { Class test } \\
\text { std. deviation } \\
\text { (\%) }\end{array}$ & $\begin{array}{c}\text { Final } \\
\text { examination } \\
\text { mean (\%) }\end{array}$ & $\begin{array}{c}\text { Final } \\
\text { examination } \\
\text { std. deviation (\%) }\end{array}$ \\
\hline Always & 77.1 & 10.4 & 67.2 & 16.4 \\
Frequently & 73.5 & 12.3 & 62.0 & 19.6 \\
Sometimes & 67.1 & 12.9 & 61.3 & 19.9 \\
Rarely & 60.7 & 17.0 & 54.4 & 22.8 \\
Never & 64.4 & 13.1 & 61.3 & 16.2 \\
\hline
\end{tabular}


Table 8 Multiple comparisons of class test performance

\begin{tabular}{lccc}
\hline & & \multicolumn{2}{c}{$95 \%$ Confidence interval } \\
\cline { 3 - 4 } Factor & $p$-value & Lower (\%) & Upper (\%) \\
\hline Frequently vs. Never & $0.00^{*}$ & 2.4 & 15.9 \\
Frequently vs. Rarely & $0.00^{*}$ & 3.8 & 21.9 \\
Always vs. Never & $0.00^{*}$ & 4.6 & 20.7 \\
Always vs. Rarely & $0.00^{*}$ & 6.4 & 26.4 \\
Always vs. Sometimes & $0.01^{*}$ & 1.5 & 18.5 \\
\hline
\end{tabular}

* Significant at $p=0.05$

between university entry qualifications and class test performance, consistent with hypothesis 3c. Similarly, to formally test whether or not university entry qualifications data was correlated with degree examination performance, a Pearson correlation was computed for university entry point data against degree examination performance. It was found that there was a significant correlation $[r=0.19, p=0.01]$ at the $p=0.05$ level of confidence. Thus, there is a very low, positive relationship between university entry qualifications and class test performance, concurrent with hypothesis 3d.

\section{Discussion}

The results obtained indicate that, overall, students gave a positive assessment of the range of question bank questions and the summary feedback provided, and valued the flexibility in study activities that the bank offered. The question bank level of usage was not influenced by either gender or off-campus accessibility to the Internet. Its increased use did appear to influence students' performance in the objective class test, between several degrees of usage. However, perhaps of greatest interest was that increased use of the objective question bank did not significantly influence students' final examination performance between several degrees of usage. That is, if you include students' performance in their degree essays conducted under examination conditions, the increased use of the question bank did not improve this.

Since the question bank focuses only on objective question testing, it may be deduced that its benefit to students is therefore only limited to objective test forms of assessments. It does not appear to improve their performance in written exam essays. This is despite the hopes and expectations of academic staff that students' familiarization with the concepts, 
theories, authors, models and research, through the use of objective testing, will translate into higher quality written answers. Many lecturers who use objective testing, draw upon the foreign language learning analogy. They see it as helping students to develop the 'vocabulary' of a discipline, so that they can go on to use it in 'conversations' and 'prose', equivalent to assignment writing and essay degree writing. The findings of this research suggest that this is not happening.

\section{Future research}

First, this study has considered only one class of students in one academic subject, using one question bank associated with one textbook. However, all publishers are now providing websites containing objective question banks to accompany their top-selling introductory textbooks in all subjects. It would be useful to confirm or reject the lack of link discovered here in other subjects. Second, student performance in tests that mirrored the objective test format of the question bank did appear to be influenced by a greater degree of usage of the bank. However, further studies could explore the underlying reasons why final examination performance (which included non-objective testing) was not significantly influenced by greater usage. What exactly prevents students incorporating what they have learned for the objective test in their essay answers? Third, this study concentrated on one year-group within a single university. Wider research can determine the true extent of business and management students' usage of the publishers' textbook question banks and their academic performance. It may well be that students at different universities and in different year-groups will be affected by question bank usage in different ways. However, the findings of this study have been consistent with the literature on CAL in other academic fields.

\section{References}

ARbaugh, J. B. (2000) 'Virtual Classroom Characteristics and Student Satisfaction with Internet-based MBA Courses’, Journal of Management Education 24(1): 32-54.

BarRetT, E. \& Lally, v. (1999) 'Gender Differences in an On-line Learning Environment', Journal of Computer Assisted Learning 15(1): 48-60.

BIGELOW, J. D. (1999) 'The Web as an Organizational Behaviour Learning Medium', Journal of Management Education 23(6): 635-50.

BLAnd, G. C. (2002) The Development of Management Courseware For the Clyde Virtual University. Dissertation presented for the degree of MSc in Information Technology. University of Glasgow, Glasgow.

Buchanan, T. (2000) 'The Efficacy of a World-Wide Web Mediated Formative Assessment', Journal of Computer Assisted Learning 16(3): 193-200.

BUCHAnAN, D. \& HUCZynski, A. (2004) Organizational Behaviour: An Introductory Text. Fifth edn. London: FT Prentice Hall. 
DAvies, M. L. \& Crowther, D. E. A. (1995) 'The Benefits of Using Multimedia in Higher Education', Active Learning 1: 3-6.

GOFFE, W. L. \& SOSIN, K. (2005) 'Teaching with Technology: May You Live in Interesting Times', Journal of Economic Education 36(3): 278-91.

Grabe, M. \& Sigler, E. (2002) 'Studying Online: Evaluation of an Online Study Environment', Computers and Education 38(4): 375-83.

HaWorth, B. \& Davidson, A. B. (2000) 'The Determinants of Web Use Within An Economics Principles Course', The Internet and Higher Education 2(4): 197-209.

human, S. E., Kilbourne, L. M., Clark, T. D., Shriberg, A. \& CunNingham, B. (1999) 'Using Web-enhanced Instruction in an Interpersonal Skills Course', Journal of Management Education 23(5): 584-606.

Johnston, S. P. \& HUCZynski, A. (2004) 'Textbook Publishers' Dedicated Student Websites: A Descriptive Analysis', The International Journal of Management Education 4(2): $47-56$.

KENNEDY, P., AGARWAL, R. \& DAY, A. E. (1998) 'The Impact of the Internet on Economic Education', Journal of Economic Education 29(2): 99-110.

KIPLING, P. \& Wilson, T. D. (2000) 'Publishing, Bookselling and the World Wide

Web’, Journal of Librarianship and Information Science 32(3): 147-53.

MACDONAlD, Z. \& SHields, M. A. (1998) 'WinEcon: An Evaluation', Journal of Economic Surveys 12(2): 221-31.

MCINNES, W. M., PYPER, D., VAN DER MEER, R. \& Wilson, R. A. (1995)

'Computer-aided Learning in Accounting: Education and Managerial Perspectives', Accounting Education 4(4): 319-34.

MCINTYRe, D. R. \& WOlF, F. G. (1998) 'An Experiment with WWW Interactive Learning in University Education', Computers and Education 31: 255-64.

MAKI, W. S. \& MAKI, R. H. (2001) 'Mastery Quizzes on the Web: Results from a

Web-based Introductory Psychology Course', Behaviour Research Methods, Instruments, and Computers 33(2): 212-6.

MeISel, S. \& MARX, B. (1999) 'Screen to Screen Versus Face to Face: Experiencing the Differences in Management Education', Journal of Management Education 23(6):

719-31.

Meristotis, J. P. \& Phipps, R. A. (1999) 'What's the Difference?', Change 31(3):

$13-17$.

Peek, R., pomerantz, J. \& Paling, S. (1998) 'The Traditional Scholarly Journal

Publishers Legitimize the Web', Journal of the American Society for Information Science 49(11): 983-9.

POSEy, K. H. (2000) 'The Utility of Publishers' Websites', Journal of Scholarly Publishing $31(2): 77-86$.

SANGSTER, A. (1992) 'Computer-based Instruction in Accounting Education’, Accounting Education 1(1): 13-32.

scheschy, v. M. (1999) 'Publishers on the Web: From Addison to Ziff', Library

Collections Acquisitions \& Technical Services 23(1): 73-8.

Shiratuddin, N. (2005) 'E-Books in Higher Education: Technology, E-Marketing

Prospects and Pricing Strategy', Journal of Electronic Commerce in Organizations 3(2): 1-16. SPellman, G. (2000) 'Evaluation of CAL in Higher Education Geography', Journal of

Computer Assisted Learning 16(1): 72-82.

Stone, A. (1998) 'Survey of Electronic Publishing', Scholarly Communications Report 26(December): 12-13.

to key, M. (2002) 'On-line Facilities for Management Education Provided by 
Publishers' Web Sites', BEST - The Newsletter of the Business Education Support Team 3(1): $10-12$.

TuCKMan, B. W. (2000) 'The Use of Frequent Testing to Increase Students'

Motivation to Achieve', paper presented at the 7th Workshop on Achievement and

Task Motivation: An International Conference on Motivation, Leuven, Belgium. WANG, A. Y. \& NEWLin, M. H. (2000) 'Characteristics of Students Who Enrol and

Success in Psychology Web-Based Classes’, Journal of Educational Psychology 91: 137-43. WARD, M. \& NEWLANDS, D. (1998) 'Use of the Web in Undergraduate Teaching', Computers and Education 31(2): 171-84.

WORThington, E. L., Welsh, J. A., ARCHer, C. R., Mindes, E. J. \& FORSYTh, D. R. (1996) 'Computer-assisted Instruction as a Supplement to Lectures in an Introductory Psychology Class', Teaching of Psychology 23(3): 175-81.

\section{Biographical notes}

SCOTt PAUl JOHNSTON is a statistician in the UK Civil Service.

ANDRZEJ HUCZYNSKI is Senior Lecturer in Organizational Behaviour in the School of Business and Management at the University of Glasgow, Scotland, UK.

Address: School of Business and Management, University of Glasgow, Gilbert Scott Building, West Quadrangle, Glasgow G12 8QQ, UK.

[Email: A.A.Huczynski@mgt.gla.ac.uk] 